\title{
Case of Cutaneous and Soft Tissue Botryomycosis
}

\author{
D. Bhuyan ${ }^{1}$, D. Damodaran², B. Das 3 , U. Sarma ${ }^{4}$
}

${ }^{1}$ Department of Radiology, Gauhati Medical College and Hospital, Guwahati, Assam, India. ${ }^{2}$ Department of Radiology, Gauhati Medical College and Hospital, Guwahati, Assam, India. ${ }^{3}$ Department of Radiology, Gauhati Medical College and Hospital, Guwahati, Assam, India. ${ }^{4}$ Department of Radiology, Gauhati Medical College and Hospital, Guwahati, Assam, India.

\section{INTRODUCTION}

Botryomycosis is a chronic granulomatous reaction to bacterial infection, most commonly caused by Staphylococcus aureus, and Pseudomonas sp., which contains granules resembling the sulphur granules of actinomycosis. The various underlying predisposing factors described for botryomycosis include trauma, diabetes mellitus, lung diseases, corticosteroid therapy, and HIV infection. Although many bacteria have been known to cause botryomycosis, Staphylococcus aureus is the most common organism. We report a case of cutaneous and soft-tissue botryomycosis with radiologic findings including $\mathrm{X}$-ray, $\mathrm{CT}$ and MRI.

\section{PRESENTATION OF CASE}

A 24-year-old man was admitted with a mass in the right foot and ankle region for the past 12 months that has been slowly increasing in size for the past 8 months. The patient was a farmer with no significant history of trauma or infection. The lesions started as a pea-sized dome shaped on foot which gradually progressed over 1 year to become more hypertrophic and involved foot and ankle region. There was occasional pain, pus discharge and bleeding. Physical examination revealed a large fungating soft-tissue mass in the dorsum, medial and lateral aspects of right feet and ankle (Figure 1) measuring approximately 10 x $11 \mathrm{~cm}$. Routine laboratory tests were unremarkable.

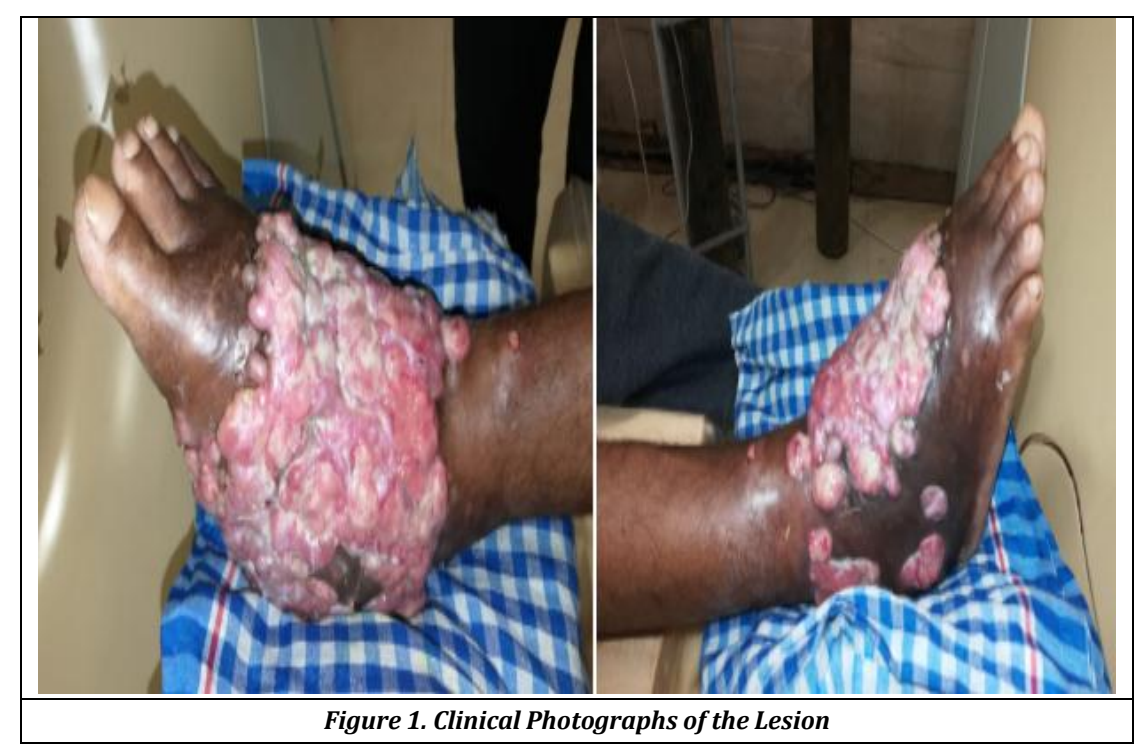

Corresponding Author: Dr. Dijesh Damodaran, USHASS, NR, PHC, Kandangali, Payyannur, Kannur-670307, Kerala, India.

E-mail:dijeshd@gmail.com

DOI: $10.14260 / j e m d s / 2019 / 730$

Financial or Other Competing Interests: None.

How to Cite This Article:

Bhuyan D, Damodaran D, Das B, et al. Case of cutaneous and soft tissue botryomycosis. J. Evolution Med. Dent. Sci. 2019;8(44): 3368-3370, DOI 10.14260/jemds/2019/730

Submission 27-11-2019, Peer Review 19-10-2019, Acceptance 26-10-2019, Published 04-11-2019.

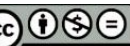


X-Ray showed an ill-defined soft tissue lesion involving ankle and feet region on right side causing erosions on tarsals and metatarsals along with osteopenia of the tarsal, metatarsal bones, distal tibia and fibula. CT revealed a multilobulated infiltrative soft tissue lesion involving multiple tissue planes causing bone infiltration, erosions involving tarsal, metatarsal bones along with solid and sunburst periosteal reaction (Fig. 2).

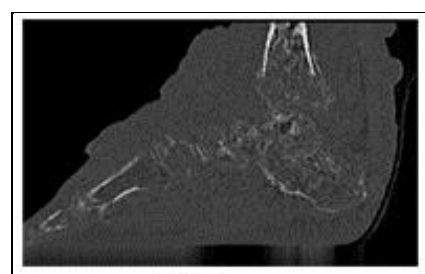

Fig. a

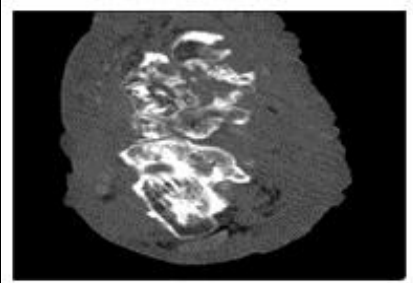

Fig. $c$

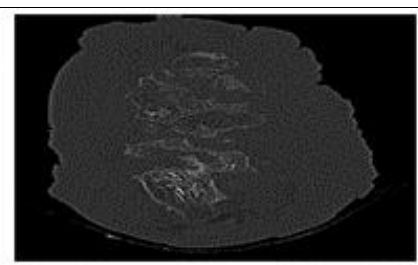

Fig, b

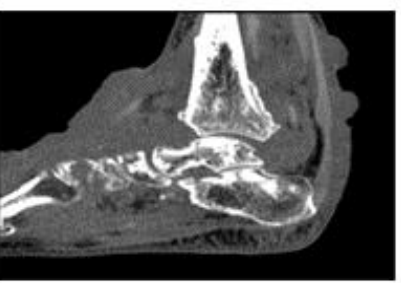

Fig, d

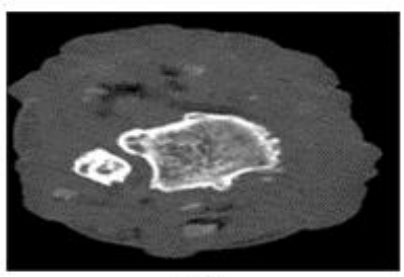

Fig, e

Figure 2. Sagittal (a,c) and axial CT (b,d) images of foot and ankle with bone $(a, b)$ and soft tissue $(c, d)$ algorithm showing ill-defined infiltrative soft tissue lesion bony extension, osteoporosis, erosions and sun burst periosteal reaction $(e)$

MR imaging, showed a heterogeneously enhancing illdefined large multilobulated infiltrating soft tissue lesion involving skin, subcutaneous tissue, muscles, ligaments, tendons and bone of feet. The lesion was iso-intense on T1WI and heterogeneously hyperintense on $\mathrm{T} 2$ weighted images. No obvious high T1 signal to suggest fat or haemorrhage was present. Few T2 hyperintense cystic areas with T2 hypointense rim and T2 hypointense dot within was noted within the lesion (Dot sign). Multiple erosions were noted in multiple tarsal and metatarsal bones. Diffuse bone marrow oedema of tarsal bones, metatarsal bones, lower end of tibia and fibula. No diffusion restriction was noted on DWI. The mass enhanced heterogeneously after gadopentetate dimeglumine was administered. (Fig. 3)

Incisional biopsy was done. The gross specimen revealed a raised soft to friable grey white lesion on skin measuring $5 \times 3$ x $2 \mathrm{~mm}$. Cut section is grayish white. On microscopy, suppurative nodules in the dermis with numerous neutrophils and scattered lymphocytes and few plasma cells were seen. A small light-coloured grain is seen in the midst of inflammatory nodule. This is made of tiny coccoid bacilli and has an eosinophilic rim (Fig. 4). The patient was treated with IV antibiotics.
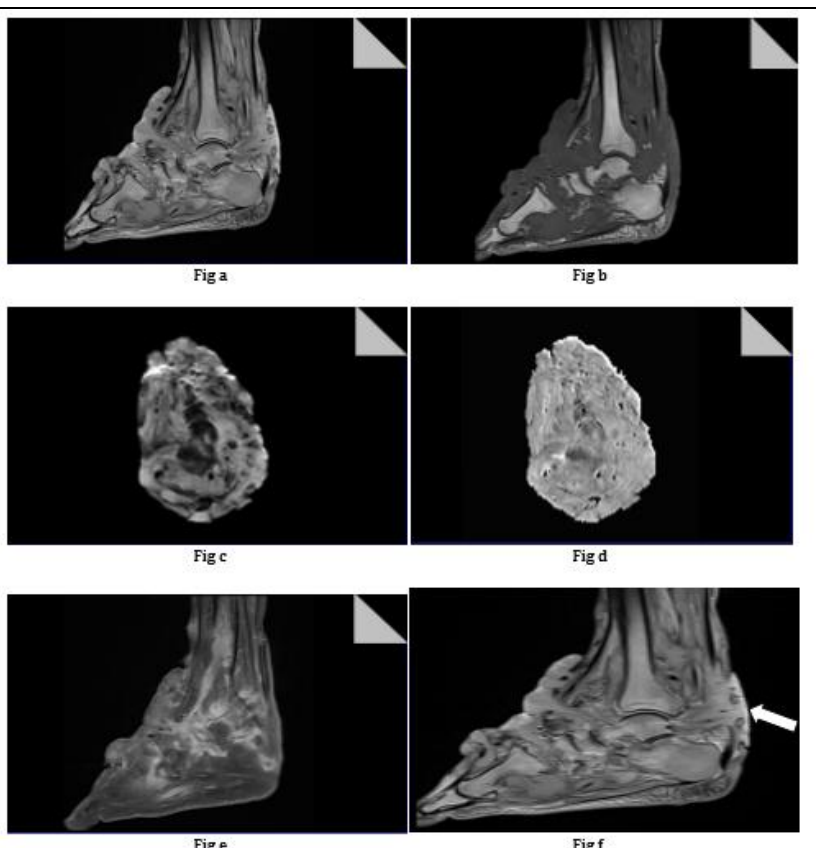

Fig

Figure 3. Sagittal T2 and T1 WI (a and b) showing ill-defined infiltrative lesion in foot and ankle appearing T2 hyperintense (a) and $T 1$ isointense (b). No diffusion restriction on DWI (c) with hyperintensity on ADC (d). (e) Post contrast T1FS showing heterogeneous enhancement. (f) Showing dot sign.

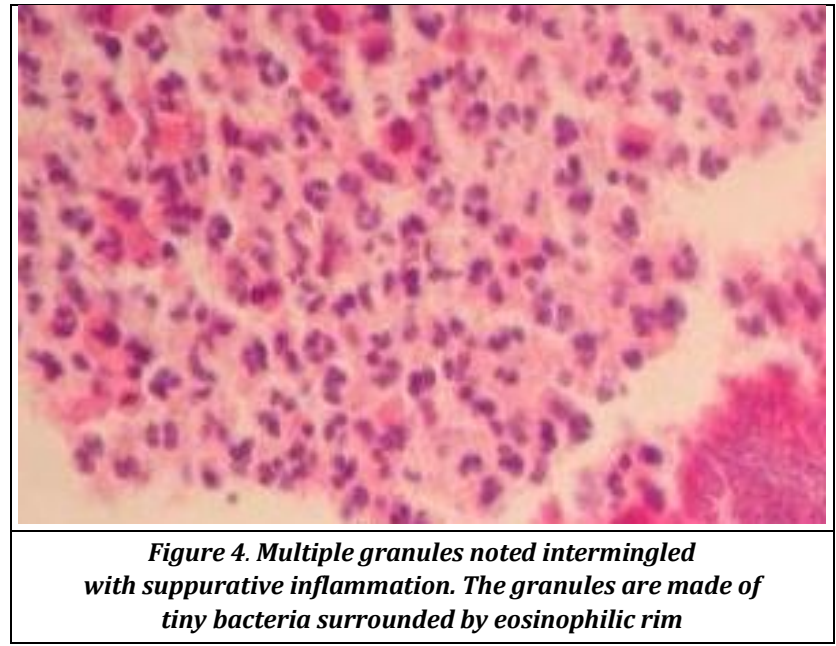

DISCUSSION

Botryomycosis is a rare, chronic, suppurative disease that is often mistaken clinically and histologically for a fungal infection. Other terms used to describe this condition include actinophytosis, staphylococcosis, bacterial pseudomycosis, and granular bacteriosis. The characteristic histologic feature of botryomycosis is a cluster of bacteria found within an eosinophilic matrix or capsule, giving the appearance of granules mimicking the sulphur granules of actinomycosis.[1] It was first considered a fungal infection, thus the term botryomycosis (Botrys - bunch of grapes, mycosis - fungal origin). Later, the bacterial aetiology was discovered, and other terms were reported.[1,2] 
It was first described by Bollinger, in 1870 , as a granulomatous lesion after horse castration. In 1884, Rivolta associated the disease to fungal cause and hence called it botryomycosis.[3] First case in humans was described by Opie in 1913. Magrou, in 1919, isolated Staphylococcus aureus as the causative agent.[4] In 1959, Winslow classified the disease as cutaneous and visceral forms.

The most frequent etiological agent is Staphylococcus aureus (40\%), followed by Pseudomonas spp. (20\%). Other microorganisms already reported are Escherichia coli, Proteus vulgaris, Bacillus spp., Actinobacillus lignieresii, etc. These organisms were either isolated singularly on in some cases in association with other organisms. This disease has two patterns of organ involvement.[5] The more common type is cutaneous, which involves the skin, subcutaneous soft-tissue, muscle, and bone. The visceral type involves the lungs, liver, tongue, orbits, bowel, brain, kidneys, or prostate.

The cutaneous form is a chronic suppurative granulomatous process with sinuses, fistulas, and multiple ulcerated nodules. Exposed surfaces of skin, such as the hands, feet, and head, are more commonly involved. Muscle and bone may be involved secondarily by contiguous extension. In many patients, no apparent predisposing condition or disease has been found. Some cases have followed trauma or associated foreign body in the soft tissues. No characteristic imaging manifestations for botryomycosis are present in the literature.[6] The "dot-in-circle" sign, seen as tiny hypointense foci within the hyperintense spherical lesions, was initially described by Sarris et al., in 2003 on T2W, STIR, and T1W fatsaturated gadolinium-enhanced images is considered to be specific for actinomycosis.[7] Treatment of botryomycosis usually involves a prolonged course of IV antibiotics and in some cases surgical resection and drainage. The prognosis of cutaneous botryomycosis is generally better than the visceral type. $[8]$

\section{REFERENCES}

[1] Mehregan DA, Su WP, Anhalt JP. Cutaneous botryomycosis. J Am Acad Dermatol 1991:24(3):393-6.

[2] Bonifaz A, Carrasco E. Botryomycosis. Int J Dermatol 1996;35(6):381-8.

[3] Opie EL. Human botryomycosis of the liver. Arch Intem Med 1913;11(4):425-39.

[4] Magrou J. Les formes actinomycotiques du staphylococque. Ann Inst Pasteur Lille 1919;33:344-74.

[5] Winslow DJ. Botryomycosis. Am J Pathol 1959;35(1):15367.

[6] Chu WO, Fruauff A, Rivas R, et al. MR finding in cutaneous botryomycosis. Am J Roentgenol 1994;163(3):647-8.

[7] Sarris I, Berendt AR, Athanasous N, et al. MRI of mycetoma of the foot: two cases demonstrating the dot-in-circle sign. Skeletal Radiol 2003;32(3):179-83.

[8] Hacker P. Botryomycosis. Int J Dermatoli 1983;22(8): 455-8. 